\title{
FORMAÇÃO CONTINUADA E UM OLHAR HISTÓRICO-CRÍTICO-CULTURAL PARA PENSAR POSSIBILIDADES DE ENFRENTAMENTO AO ADOECIMENTO DOCENTE
}

\author{
SORAyA CUNHA COUTO VITAL \\ VANDERLEI BRAULINo Queiroz \\ SONIA DA CUNHA URT \\ Universidade Federal de Mato Grosso do Sul (UFMS), Campos Grande, Mato Grosso do \\ Sul, Brasil
}

Resumo: O objetivo deste artigo é analisar o delineamento de uma pesquisa bibliográfica acerca da formação continuada de professores, considerando como esta pode representar uma possibilidade de enfrentamento ao adoecimento docente. A análise crítica ocorre sobre o aporte teórico-metodológico da Psicologia Histórico-Cultural e da Pedagogia Histórico-Crítica. Como resultado, compreendese que pensar uma formação contínua que contribua para esse enfrentamento pressupõe considerar sua articulação com as problemáticas mais amplas da sociedade, sob o entendimento de que a cultura e as relações sociais são elementos fundamentais na constituição do professor emancipado, crítico e capaz de compreender os processos sociais. Enfim, uma formação transformadora.

Palavras-chave: Formação Continuada de Professores. Adoecimento. Enfrentamento. Teoria Histórico-Cultural.

\section{INTRODUÇÃO}

Este texto está relacionado a pesquisas que empreendem estudos referentes às possibilidades de compreensão das fundamentações teórico-metodológicas de propostas de formação continuada de professores e seu suporte à prática pedagógica, considerando a formação para a emancipação humana na sociedade contemporânea e os modos de enfrentamento ao adoecimento docente. Entende-se enfrentamento aqui como a maneira de identificar e defrontar as condições objetivas geradoras de adoecimento docente: violência, precariedade, excesso e desprestígio do trabalho professoral, entre outros fatores afins.

Seu aporte teórico-metodológico é a Psicologia Histórico-Cultural em interface com a Pedagogia Histórico-Crítica. Esta Psicologia é apresentada como uma corrente psicológica baseada no Materialismo Histórico-Dialético, assinalando a contribuição dessa abordagem para a compreensão do homem enquanto sujeito histórico e constituído nas/por meio das relações sociais.

A mesma concepção dialética fundamenta a Pedagogia Histórico-Crítica, uma teoria da educação elaborada a partir de uma concepção pedagógica em consonância 
com a concepção de mundo e de homem própria do materialismo histórico, que não permite pensar que as questões educacionais são o limite de uma ação pedagógica transformadora, mas entendê-las a partir de determinantes históricos, e que as mudanças das formas de produção da existência humana foram gerando historicamente novas formas de educação e de formação docente.

A partir de experiências profissionais com formação de professores, de resultados obtidos em pesquisa de Mestrado em Psicologia (2014-2016) a respeito de proposta de formação e seu processo de implantação em rede pública de ensino de um estado brasileiro e de realização de inventário de produções acadêmicas a respeito do adoecimento docente (2018-2019) sob os moldes de Estado do Conhecimento, um motivo especial impeliu as pesquisas de Mestrado e Doutorado em Educação (20172021) que alicerçam este artigo: a carência de investigações e questionamentos relacionados às bases teórico-metodológicas que subsidiam a formação continuada de professores e como ela pode contribuir para o enfrentamento do adoecimento docente.

Por esse motivo, o objetivo aqui é analisar o delineamento de uma pesquisa bibliográfica acerca da formação continuada de professores, considerando como esta, pensada sob a perspectiva da emancipação humana, pode representar uma possibilidade de enfrentamento ao adoecimento docente que, entre outros fatores, tem sido decorrente de um contexto de trabalho alienado e despersonalizante.

O percurso metodológico tem ocorrido desde o mês de novembro de 2019, por meio de levantamento e seleção de dados bibliográficos relacionados às temáticas das pesquisas supracitadas, acessados em livros impressos e artigos eletrônicos contidos em bancos como o Scientific Eletronic Library - SCIELO, e os de teses e dissertações de diversas universidades brasileiras, como a Universidade Federal de Mato Grosso do Sul UFMS, e a Universidade Estadual de Maringá - UEM, por exemplo. Para a busca, têm sido utilizadas as palavras-chave "formação continuada", "professores/docentes", "adoecimento" e "enfrentamento".

Até o momento, foram selecionadas 18 obras impressas, 5 dissertações e 3 teses. Porém, pelo fato de o referido estudo bibliográfico estar em andamento, apresenta-se aqui um recorte do que tem sido encontrado nas obras de autores e pesquisadores que têm apresentado contribuições a respeito da formação continuada de professores e do adoecimento docente. Para tal, são apresentados alguns entendimentos acerca dessas temáticas, analisando-os sobre o fundamento teóricometodológico da Psicologia Histórico-Cultural e da Pedagogia Histórico-Crítica, considerando como esse aporte pode apresentar contribuições para pensar uma formação continuada com um olhar emancipatório, crítico e de possibilidades de enfrentamento a esse adoecimento.

Os resultados indicam que pensar uma formação contínua que contribua para esse enfrentamento pressupõe considerar uma formação transformadora, que proponha e desenvolva ensinamentos docentes que estejam em articulação com as problemáticas mais amplas da sociedade, sob o entendimento de que a cultura e as relações sociais são elementos fundamentais na constituição do professor emancipado, crítico e capaz de compreender os processos sociais. 
VITAL, S. C. C.; QUEIROZ, V. B.; URT, S. da C.

\section{FORMAÇÃO CONTINUADA E ADOECIMENTO DOCENTE: CONSIDERAÇÕES BIBLIOGRÁFICAS}

No decurso das pesquisas que originam este trabalho, foi identificada uma gama de temas relacionados à formação continuada de professores e uma variedade terminológica para identificá-la, como formação contínua, formação permanente, formação em serviço e educação continuada (IMBERNÓN, 2016; CANÁRIO, 2013; CASTRO; AMORIM, 2015), por exemplo.

Segundo Canário (2013) e Castro e Amorim (2015), essa variação de termos está relacionada a questões conceituais, visto que há concepções distintas que têm disputado espaço no cenário formativo docente, baseadas nas expressões educação continuada e formação continuada. Nesse sentido, os autores consideram que:

[...] a educação significa principalmente um processo formal de ensino-aprendizagem desenvolvido em uma instituição constituída para tanto, por meio de profissionais qualificados para fazê-lo, o conceito de educação continuada aproxima as ações de uma lógica escolarizante, de transferência de conhecimentos. Em sentido oposto, a formação continuada desenvolver-se-ia menos sob a perspectiva de um programa escolar e mais de acordo com uma vertente de treinamento, para a qual se pressupõe que os educandos devem e podem ser treinados a fim de melhorarem seu desempenho. (CASTRO; AMORIM, 2015, p. 39).

Imbernón (2016, p. 7), por sua vez, considera que a formação permanente deve estar relacionada à compreensão da profissão docente. Isto é, a profissão docente deve abandonar a concepção educacional predominante no século XIX, obsoleta para os cidadãos de uma "sociedade democrática, plural, participativa e integradora", então a formação dos professores deve romper com as diretrizes de origem "centralista, transmissora, selecionadora, individualista".

Para que tal formação permanente aconteça, o mesmo autor assevera que é preciso:

[...] superar definitivamente os enfoques tecnológicos, funcionalistas, burocratizantes, aproximando-se, ao contrário, de seu caráter mais relacional, mais dialógico, mais cultural-contextual e comunitário, em cujo âmbito adquire importância a relação que se estabelece entre todas as pessoas que trabalham dentro e fora da instituição (escolar). (IMBERNÓN, 2016, p. 8, acréscimo nosso).

Acerca disso, Vital e Urt (2019a) consideram a importância de pensar a função da formação docente e a do professor como o agente primordial no processo formativo do sujeito, e de tecer questões relativas à estrutura educativa e de seu suporte à transição de paradigma que o debate acerca da educação pressupõe.

André (2016, p. 19), ao considerar essa formação, postula que "há muita atenção ao processo de formação, mas, frequentemente, nos esquecemos do outro lado da formação, a quem ela se destina, para que ela existe". E continua afirmando que a formação precisa conduzir a uma ação docente efetiva, que faça com que a maioria dos 
alunos se aproprie dos conhecimentos "e das atitudes necessárias para se desenvolverem e se tornarem cidadãos críticos e criativos" (ANDRÉ, 2016, p. 19).

Gatti (2004), no que lhe concerne, sinaliza que a formação continuada docente tem sido uma tarefa complexa pelo fato de o professor necessitar de formação aprofundada nos conteúdos de sua área de atuação associada à formação permanente em investigação científica e em didática. A esse respeito, as reflexões de Oliveira (2004) apontam que é preciso considerar o professor em processo de formação como um sujeito em permanente constituição, desenvolvimento e aprendizagem, porque é muito mais do que dizer "o professor ensina" ou "o professor dá aulas", por exemplo. Segundo a autora, "É preciso entender de forma aprofundada das diferentes práticas culturais, a construção compartilhada de sentidos e significados, a internalização de modos de fazer, de pensar e de produzir a cultura em cada âmbito concreto da cultura" (OLIVEIRA, 2004, p. 217).

Charlot (2005) afirma, contudo, que:

\begin{abstract}
O problema é que [...] para ajudar os professores a enfrentarem as novas situações de ensino, oferece-se a eles hoje uma formação de tipo universitário, em que predomina um acúmulo de conteúdos disciplinares. Esses conteúdos não são inúteis [...], mas não se vê realmente em que eles permitem aos professores resolver os problemas com os quais são confrontados. (CHARLOT, 2005, p. 86).
\end{abstract}

O autor ainda declara que pensar o processo formativo contínuo do professor é pensar que sempre há uma mutação em curso, e que em seu contexto a "questão da educação e da cultura são elementos essenciais" (CHARLOT, 2005, p. 86). Para Charlot (2005, p. 86), não devem estar em jogo somente "as novas formas de organização das sociedades", mas "a definição do humano e do sujeito é que está em jogo atualmente".

Diante desses dados, esclarece-se que neste trabalho a formação continuada de professores é entendida como a que acontece em processo permanente/constante após a formação inicial, intentando contribuir para o aperfeiçoamento de saberes necessários à atividade docente (VITAL; URT, 2019a).

No que tange às concepções a respeito do adoecimento de professores, Penteado e Souza Neto (2019, p. 135), entre outros autores, consideram que se trata de uma problemática também denominada mal-estar e sofrimento, que está "vinculada à história do trabalho docente, aos modos de ser/estar na ocupação e à cultura do magistério". Sua pesquisa bibliográfica também aponta, sob o olhar de Gasparini, Barreto e Assunção (2005), que:

No Brasil a literatura acerca dos problemas de saúde e processos de mal-estar, sofrimentos e adoecimentos de professores mostra a prevalência dos transtornos mentais e comportamentais, dos distúrbios da voz e das doenças osteomusculares e do tecido conjuntivo, os quais atingem os docentes do ensino público e particular de todos os níveis, disciplinas e momentos da carreira. (PENTEADO; SOUZA NETO, 2019, p. 136). 
VITAL, S. C. C.; QUEIROZ, V. B.; URT, S. da C.

Estudos como os de Gonçalves et al (2015), por exemplo, investigam o conceito de adoecimento e apontam que há uma tendência em considerá-lo para além dos aspectos biológicos, com o acréscimo da dimensão psicológica e socioeconômica. Para esses autores a definição de doença/adoecimento não está ligada apenas à experiência pessoal e sua relação com um problema de saúde, mas também diz respeito ao significado que lhe é conferido.

Ao considerar conceituações como essas, Alonso (2004) afirma que há um paradigma biomédico de saúde e doença, que parte do modelo cartesiano, de divisão entre corpo e mente, mas que, segundo sua compreensão, a doença, ou o adoecimento, possui facetas biológicas, subjetivas e sociais, assim como a saúde. Já para Canguilhem (2009), o patológico pode ser entendido como parte do viver e, por isso, normal - de modo que o estado fisiológico propende para o são. A diferença entre doença e saúde está em conseguir ou não alterar sua condição. Se faltam ao sujeito os recursos para modificar o estado patológico, então aí está a doença.

Papareli, Sato e Oliveira (2011) consideram que o processo saúde-doença é socialmente construído, por isso faz-se necessário superar as falácias que induzem à culpabilização do indivíduo e identificar as bases sociais, históricas e econômicas presentes no processo do adoecimento. Pesquisas como as de Andrade (2014) e Mezzari (2017), por exemplo, apresentam que as mudanças no mundo do trabalho têm gerado precarização do trabalho docente e maior suscetibilidade ao adoecimento do professor.

Nessa perspectiva é que Facci et al. (2017) indicam que diagnósticos médicos consideram a preponderância do adoecimento de ordem psicológica em professores, e que esse tem relação com o processo de trabalho, mais especificamente à precarização do trabalho docente e à alienação a qual estão submetidos em sua prática profissional.

[...] com a divisão do trabalho, com a fragmentação do processo de trabalho, ocorre o estranhamento deste trabalho e o docente não se vê mais como partícipe do processo de humanização do aluno. Ele mesmo, nestas condições em que desenvolve sua atividade pedagógica, tem poucas condições para se humanizar - no sentido de se apropriar das elaborações mais desenvolvidas criadas pelos homens. (FACCl et al., 2017, p. 132).

Com base nessa premissa, pode-se pontuar então que a inegável influência paradigmática do neoliberalismo impõe à formação continuada de professores o papel de opção meramente técnica, voltada para o mundo do trabalho, que propõe atender às demandas do capital, que desconsidera a estrutura societária contraditória, composta por modismos educacionais, que subsidia uma visão acrítica da sociedade capitalista e apresenta-se como instrumental para a não superação da unilateralidade humana.

Em meio a essa realidade socioeconômica desigual, o acesso à riqueza do desenvolvimento cultural, científico e tecnológico, por exemplo, elaborado no decurso do movimento histórico da constituição da sociedade, está negado à maioria, o que reforça contradições - inclusão/exclusão, resistência/desistência - que reverberam na realidade do trabalho docente e tornam-se fatores que podem levar ao adoecimento.

Em sentido emancipatório, Barros e Girotto (2019) afirmam que, com as novas demandas do mercado de trabalho e dos processos de aprendizagem e desenvolvimento do sujeito no contexto da sociedade atual, as propostas de formação 
continuada precisam estar atentas às exigências que influenciam e desafiam a maneira de os professores verem e agirem sobre sua atividade principal - "o ensino baseado em conhecimentos" (BARROS; GIROTTO, 2019, p. 79) científicos elaborados. Aliado a isso, consideram que é importante pensar essa formação a partir da apropriação de um método de análise da realidade, que compreenda e perceba o real, analise-o em sua complexidade e desenvolva ações educativas que proporcionem luta a favor da emancipação.

O aporte histórico-cultural compreende o professor como um ser social, uma síntese de múltiplas determinações, que, pelo fato de não trazer dentro de si uma essência já delimitada, não pode existir isoladamente. Logo, a formação docente deve considerar seu trabalho, atividade adequada a um fim, como atividade principal, ou seja, como prática social que pode possibilitar seu desenvolvimento humano, nos aspectos pessoal e profissional.

A partir dessa visão, pode-se pensar que a ruptura com a alienação imposta pelas proposituras da divisão social do trabalho também pode perpassar por uma formação ininterrupta, que possibilite continuamente o desenvolvimento de professores e contribua para um olhar de possibilidades de enfrentamento ao seu adoecimento psíquico. É nesse sentido que Araujo (2009, p. 8) afirma que formar "é sempre um verbo que se conjuga no gerúndio", porque preconiza uma ação contínua, permanente, em andamento, e indica um processo ainda não finalizado, que está em constante desenvolvimento.

Neste artigo, considera-se que, devido à complexidade da atividade docente, é possível perceber também que professores são alvo das enfermidades relacionadas ao sofrimento físico e psíquico, portanto merecem ser observados com atenção. Essas proposições fundamentam as considerações a seguir, relativas à inter-relação entre Psicologia Histórico-Cultural e Pedagogia Histórico-Crítica para possível aporte ao pensamento de uma formação continuada com um olhar de perspectivas de enfrentamento ao seu adoecimento.

\section{PSICOLOGIA HISTÓRICO-CULTURAL E PEDAGOGIA HISTÓRICO-CRÍTICA: FORMAÇÃO HUMANA E ENFRENTAMENTO AO ADOECIMENTO DOCENTE}

O processo de formação humana pode ser entendido como um processo de humanização de sujeitos, mas não de quaisquer sujeitos. Segundo Miller (2019), é:

[...] um processo de humanização dos sujeitos sócio-históricos, pelo qual estes desenvolvem suas condutas humanas superiores constituídas no processo de apropriação da cultura historicamente elaborada, que ocorre por meio da sua ativa participação nas relações sociais estabelecidas entre eles e as gerações precedentes. (MILLER, 2019, p. 9).

É um processo permeado de aprendizagem, em que os sujeitos desenvolvem o domínio de distintas formas de comunicação com outros, que acontece em caráter 
VITAL, S. C. C.; QUEIROZ, V. B.; URT, S. da C.

coletivo, de cooperação mútua, em que cada ser humano aprende por toda a sua existência nas relações de convivência social.

Em contexto histórico-crítico-cultural, faz-se importante considerar que o entendimento a respeito da formação e do desenvolvimento humano parte de dois pressupostos, entre outros. Primeiro, Leontiev (1978, p. 261) apresenta que, "de longa data, é o homem considerado como um ser à parte, qualitativamente diferente dos animais". Segundo, Marx e Engels (1996, p. 69) asseveram que há na história dos homens, de forma correlacionada, um "contínuo trabalhar e criar sensíveis", e que "esta produção é a base de todo o mundo sensível tal e como agora existe".

A premissa considerada por Leontiev (1978) está ancorada em sua compreensão acerca da passagem dos animais ao homem como um longo processo que compreende uma série de estágios. Mais especificamente, no terceiro estágio da formação do homem, que denomina de "viragem", considera que este se distingue fundamentalmente dos animais porque possui "aptidão para formar aptidões especificamente humanas" (LEONTIEV, 1978, p. 263). Após seu nascimento, o homem desenvolve-se em humano não por causa de suas particularidades e variações biológicas, mas essencialmente porque a humanização acontece no processo das "condições de vida social" e nos "fenômenos externos da cultura material e intelectual" (LEONTIEV, 1978, p. 265).

O pressuposto apresentado por Marx e Engels (1996) também encontra ancoragem nessa compreensão, visto que em sua análise sobre o processo de formação humana afirmam que "os homens em sua conexão social dada, em suas condições de vida existentes, que fizeram deles o que são" (MARX; ENGELS, 1996, p. 69).

Marx (2004), mais especificamente, sistematiza seus estudos acerca dessa formação de acordo com o modo capitalista de produção da vida, considerando que o homem "tem sua existência não enquanto homem, mas enquanto trabalhador" (MARX, 2004, p. 91), e continua: "O homem nada mais é do que trabalhador e, como trabalhador, suas propriedades humanas o são apenas na medida em que o são para o capital, que lhe é estranho" (MARX, 2004, p. 91, grifo do autor).

Nesse processo capitalista, as considerações de Marx (2004) reputam que a formação humana passa por estranhamento de sentido, do ser para o ter, e, nesse caso, refere-se ao homem como "mercadoria humana, o homem na determinação da mercadoria; ela o produz [...] como um ser desumanizado tanto espiritual quanto corporalmente - imoralidade, deformação, embrutecimento de trabalhadores e capitalistas" (MARX, 2004, p. 92-93, grifo do autor).

A partir da premissa marxista, o modo de produção capitalista estabelece aos homens um sistema de exploração de uns sobre os outros, que pode ser considerado coerente para o desenvolvimento do regime de classes, mas não para o desenvolvimento humano. Seu caráter crítico e revolucionário concebia uma sociedade desprovida da alienação humana produzida pelo capital, uma sociedade em que o trabalhador desenvolvesse suas capacidades porque produziria sua existência e criaria a consciência do seu ser social, desenvolvendo a condição de ser universal e livre.

Leontiev (1978), apoiando-se em Marx, observava que o trabalho é uma atividade que distingue o ser social do ser natural, isto é, define a especificidade do ser humano como um ser histórico, pelo fato de o trabalho possuir certas características: a de ser uma 
atividade que se materializa em um produto social, um produto que não é mais um objeto meramente natural, um produto que é uma objetivação da atividade e do pensamento do ser humano. (URT, 2016, p. 18).

Vê-se então que o processo de formação do sujeito é sempre um processo educativo, que acontece no interior da prática social, porque o desenvolvimento da estrutura humana ocorre na apropriação que faz da experiência histórico-cultural. Esse processo indica que ao mesmo tempo em que o sujeito se apropria das formas culturais e as internaliza também transforma e realiza intervenções nelas.

A partir desses pressupostos, cabe aqui atentar para o papel da educação como um elemento essencial à formação do ser social, considerando a formação como um meio de apropriação dos conhecimentos e possibilidade para a emancipação humana, visto que há uma imensa riqueza material e intelectual produzida historicamente pelos homens, e um mundo de objetos, instrumentos e ferramentas materiais e intelectuais constituindo a cultura humana.

Sobre essas bases, entende-se que formar o homem no sentido da emancipação significa relacionar sua atividade, o trabalho, com sua formação cultural, logo, a atividade docente, o trabalho do professor, é considerada sua atividade principal, entendida como possibilidade de emancipação humana. Isso quer dizer que pensar em formação docente é pensar em trabalho docente e em transformação e emancipação docente.

Nessa perspectiva, compreende-se que a formação docente é necessária, mas, para que atenda aos pressupostos desenvolvimentais dialéticos, precisa ser pensada e organizada a partir de processos formativos que produzam atividades de transformação, "constituídas pelas unidades motivo-objeto, conteúdo-método, imitação-criação e ruptura-desenvolvimento" (LONGAREZI, 2017, p. 189). Acredita-se que a totalidade dessas unidades pode proporcionar um movimento de formação/desenvolvimento professoral a partir de uma compreensão histórico-crítico-cultural.

Essa compreensão perpassa pela defesa de uma formação docente centrada na intencionalidade pedagógica, na visão crítica de abordagens cujo enfoque supervaloriza a formação alinhada à subjetividade do professor, responsabilizando-o por seu sucesso ou fracasso profissional. A partir dessa visão, pode-se pensar que a ruptura com a alienação imposta pelas proposituras da divisão social do trabalho também perpassa pela formação docente, e que essa atividade formativa precisa possibilitar continuamente o desenvolvimento de professores, porque é compreendida como um processo de aprendizagem que produz o desenvolvimento humano.

Por isso, no âmbito de uma formação continuada pensada como possibilidade de enfrentamento ao adoecimento de professores, pode-se considerar que a Psicologia Histórico-Cultural e a Pedagogia Histórico-Crítica proporcionam subsídios para uma educação que objetive promover o desenvolvimento a partir de princípios que vão além da instrumentalização docente. Antes, que procure legitimar a formação do pensamento teórico, o conhecimento científico e a cultura.

De acordo com Saviani (2008), essas condições devem pressupor o planejamento intencional de ações didáticas e saberes historicamente sistematizados, 
VITAL, S. C. C.; QUEIROZ, V. B.; URT, S. da C.

porque tais ações, organizadas e com conteúdos significativos, representam um dado essencial para a educação do sujeito, visto que na ausência desses elementos a aprendizagem torna-se vazia e, consequentemente, se transforma numa farsa.

É nesse sentido que Saviani (2009) também tece considerações referentes à formação de professores, assinalando a precariedade das políticas e das formas estabelecidas, que não configuram um padrão consistente de preparo profissional e de enfrentamento dos diversos problemas que os acometem - aos quais acrescenta-se aqui o adoecimento.

Dentre os problemas, estão os "modelos contrapostos de formação de professores", denominados por Saviani (2009, p. 148-149) de "modelo dos conteúdos culturais-cognitivos" e "modelo pedagógico-didático". No primeiro, a formação do professor "se esgota na cultura geral e no domínio específico dos conteúdos da área de conhecimento correspondente à disciplina que irá lecionar" (SAVIANI, 2009, p. 148); e no segundo, que se contrapõe ao anterior, "a formação do professor propriamente dita só se completa com o efetivo preparo pedagógico-didático" (SAVIANI, 2009, p. 149).

Isso não quer dizer que o processo formativo docente não deva, em algum momento, perpassar pela "formação específica na área de conhecimento correspondente" (SAVIANI, 2009, p. 149), mas, para além dessa concepção, a formação "deverá assegurar, de forma deliberada e sistemática, [...] a preparação pedagógicodidática, sem a qual não estará, em sentido próprio, formando professores" (SAVIANI, 2009, p. 149).

Duarte (2003) também se pronuncia acerca dos dilemas enfrentados pela sistematização e a concepção de conhecimentos que devem ser abarcados na organização do processo de formação dos professores, considerando que:

\footnotetext{
[...] de pouco ou nada servirá a defesa da tese de formação de professores no Brasil [...], se não for desenvolvida uma análise crítica da desvalorização do conhecimento escolar, científico, teórico, contida nesse ideário que se tornou dominante no campo [...] da formação de professores [...]. De pouco ou nada servirá mantermos a formação de professores [...] se o conteúdo dessa formação for maciçamente reduzido ao exercício de uma reflexão sobre os saberes profissionais, de caráter tácito, pessoal, particularizado, subjetivo etc. De pouco ou nada adiantará defendermos a necessidade de os formadores de professores serem pesquisadores em educação, se as pesquisas em educação se renderem ao "recuo da teoria". (DUARTE, 2003, p. 618-619, grifo do autor).
}

Logo, as ações de formação docente devem ser intencionais, a fim de que possibilitem o questionamento e a reflexão sobre a importância do que está sendo ensinado, com destaque à função social do ensino no âmbito da formação dos sujeitos que estão em processo de aprendizagem, no caso deste artigo os professores em processo formativo contínuo. Considera-se que Nóvoa (2020) complementa esse entendimento, ao afirmar que essa formação deve ser organizada de forma que o professor seja "participante, não somente observador", que aja no "coletivo, em 
conjunto, a partir da dinâmica de participação, colaboração, correligionaridade e muitos diálogos" (informação verbal). ${ }^{1}$

Uma formação nesses moldes pressupõe considerar o adoecimento docente para além de uma concepção individualizante, mas vê-lo como um problema social, que está posto numa forma de estruturação da sociedade neoliberal, porque perpassa pela compreensão de que:

\begin{abstract}
O significado da atividade do professor é a ação de ensinar e de conduzir o processo de apropriação do conhecimento do aluno. Quando há a ruptura entre o significado social e o sentido pessoal, provocado pelas crises sociais, caracterizada pela consciência humana alienada, não se estabelece o alicerce subjetivo construído por essa dinâmica. (SANTOS; URT; VITAL, 2017, p. 80).
\end{abstract}

É nesse sentido que Borges (2014, p. 163) reafirma que na sociedade do capital, ao pertencer à classe trabalhadora, o professor está sujeito "à lógica de exploração da classe dominante, que detém os meios de produção. De modo que os conflitos e interesses manifestos nas contradições referentes ao trabalho sigam a lógica linear da manutenção do modo de acumulação capitalista" em voga.

A mesma autora ratifica essa concepção, afirmando que "por ser a saúde também resultante das relações do homem com o seu trabalho e com a sociedade [...], o processo de adoecimento docente tem estreita relação com a alienação do trabalho" (BORGES, 2014, p. 163). Ao considerar as concepções de Marx (2004), Borges (2014, p. 163) reitera que "o trabalho é humanização, criação, recriação; é transformação dos elementos da natureza", e, em contraponto, "o trabalho alienado é o estranhamento do trabalhador em relação" ao executado, ao produto de seu trabalho e a ele mesmo. Dessa forma, "O estranhamento corresponde ao afastamento do homem de sua essência humana, sua reificação [...], sua conversão em coisa" (BORGES, 2014, p. 163).

Ao submeter-se a um trabalho alienado, o professor sente-se degradado, perde sua espontaneidade e sua capacidade criativa, torna-se engessado dentro de uma lógica que não o satisfaz (MARX, 2004). A evidência dessa realidade de sofrimento e consequente adoecimento pode ser encontrada nos altos índices de licenças e/ou atestados médicos, nos afastamentos de professores das salas de aula e dos processos de readaptação docente.

A título de exemplo, pode-se considerar o conteúdo do programa Profissão Repórter (BARCELOS, 2019), veiculado pela TV Globo no dia 18 de dezembro de 2019 e disponível no Globoplay, intitulado Professores lutam contra doenças e até agressões para continuar na profissão, que exibiu depoimentos de docentes que faziam uso de remédios controlados, expressavam insatisfação com carga excessiva de trabalho, reclamavam de indisciplina e agressões de alunos em sala de aula e engrossavam as estatísticas brasileiras relativas ao adoecimento docente e à realidade cotidiana de

\footnotetext{
${ }^{1}$ Informação fornecida por António Nóvoa na Webconferência "Formação de Professores em Tempo de Pandemia", promovida pelo Instituto lungo em 23 jun. 2020. Disponível em: https://www.youtube.com/watch?v=ef3Y QcbERiM Acesso em: 30 jun. 2020.
} 
VITAL, S. C. C.; QUEIROZ, V. B.; URT, S. da C.

quem estava rotineiramente nas filas das perícias médicas do INSS - Instituto Nacional do Seguro Social. ${ }^{2}$

Infelizmente, a realidade de 2020 não tem sido melhor. A Covid-19 e sua devastação pandêmica, que até meados de agosto apresentou aproximadamente 21 milhões de infectados no mundo e levou mais de 110 mil brasileiros a óbito, tem indicado que professores, que estavam ou não em situação de adoecimento, podem desenvolver enfermidades decorrentes desse contexto. Uma amostra tangível foi considerada no podcast da Folha de São Paulo (AMPUDIA; DEODORO, 2020), veiculado em 2 de junho de 2020, com abordagem referente aos cuidados com saúde mental dos professores em tempos de coronavírus.

Segundo pesquisa apresentada nesse veículo sobre seus sentimentos durante a pandemia, realizada com mais de 7 mil docentes no Brasil, $67 \%$ consideram-se ansiosos, $38 \%$ sobrecarregados e $17 \%$ depressivos. Outros indicaram que as mudanças no mundo do trabalho e as condições precarizadas para sua realização, como home office, distanciamento social e aulas online - realidade para a qual não estavam preparados, causaram aumento de tensão e estresse.

Na sociedade guiada pelo capital a vida não está entre as prioridades, mas a produtividade e o lucro que dela advém, por isso vê-se o desmerecimento da dor e da enfermidade. No contraponto dessa visão, considera-se imprescindível pensar o adoecimento docente a partir de uma análise psicológica e pedagógica crítica, subsidiada por uma perspectiva de superação de entendimentos e práticas alienantes acerca do trabalho de professores e de sua formação continuada.

\section{CONSIDERAÇÕES FINAIS}

O delineamento da pesquisa bibliográfica que subsidia este trabalho indica que a literatura científica tem apresentado estudos e diálogos acerca da formação continuada de professores e como estes acontecem no território dos interessados pelas temáticas educacionais. Há, por exemplo, uma intensa produção acadêmica que tem justificado a preocupação com o tema - história, políticas, legislação, ensino, aprendizagem e debates a respeito de seus problemas, com consequente busca por sua qualidade, para citar alguns.

Por outro lado, no que tange ao adoecimento do professor, pode-se constatar que há pesquisas realizadas por áreas distintas à Educação, como Psicologia, Psicologia do Trabalho, Enfermagem, Fonoaudiologia, Saúde Coletiva, Educação Física, Medicina, Saúde do Trabalhador, Otorrinolaringologia, Biologia, Engenharia, Ergonomia e Fisioterapia, por exemplo. Segundo Soares e Martins (2017) e Penteado e Souza Neto (2019), há os que enfocam preponderantemente o estresse e o desgaste relacionado ao mal-estar ou adoecimento físico e mental de professores, atrelando-o ao ritmo acelerado, ao grande volume de trabalho e às condições inadequadas para realizá-lo.

Por tal constatação, objetivou-se aqui considerar bases teórico-metodológicas que contribuíssem para pensar possibilidades para um processo de formação que contribua para o enfrentamento do adoecimento docente, considerando a importância de sua articulação com as problemáticas mais amplas da sociedade, sob o entendimento

${ }^{2}$ Órgão do Ministério da Previdência Social, relacionado diretamente ao governo federal do Brasil. 
de que a cultura e as relações sociais são elementos fundamentais na constituição humana. Esse objetivo perpassa pela perspectiva de um sujeito social, cujo desenvolvimento ocorra em sua totalidade, e cuja constituição aconteça na relação com o outro, na construção coletiva do conhecimento.

Pensa-se, assim, que os pressupostos da Psicologia Histórico-Cultural e da Pedagogia Histórico-Crítica fundamentam tal propósito, porque defendem uma contínua formação docente que, de forma socializada, considere os conhecimentos científicos produzidos historicamente, com qualidade, com métodos avançados, sob a compreensão de que o professor é o agente possibilitador do processo de aprendizagem.

Entende-se também que esse arcabouço teórico pode subsidiar a busca pela superação de atuais conceitos de adoecimento e sua relação dicotômica com o de saúde, visto que os caminhos histórico-culturais e histórico-críticos propõem transformação a partir da lógica dialética, que, por sua vez, ancora o pensamento a respeito da relação entre sujeito e objeto na constituição da subjetividade humana.

Isso quer dizer que, enquanto o processo de conhecimento acerca do fenômeno adoecimento/saúde for concebido e/ou visto de forma a configurar um binômio, correse o risco de permanecer na insuficiência de ações, inclusive as que envolvem as de formação continuada de professores, que reproduzam rotineira e alienantemente o que está posto nesta sociedade neoliberal, a despeito de considerar que "a dialética é o método por excelência para dar conta de fenômeno tão evanescente e mutável, tão dinâmico e complexamente determinado" (SAMPAIO, 1998, p. 19).

A partir de uma visão crítica dos dados bibliográficos ora apresentados, compreende-se aqui que uma demanda importante para o processo de formação continuada de professores é contribuir para a superação de tais concepções, promovendo análises, diálogos, discussões acerca dos fatores constituintes do adoecimento docente para além de olhares patologizantes e despersolanizantes, por isso propõe-se romper com modelos estereotipados de educação e assumir propostas e projetos de formação docente que, segundo Vital e Urt (2017, p. 16517), "possibilitem novos modos de aquisição de conhecimento, de pensar e de agir. Que rompa com uma visão estreita de ensino e se paute em princípios que concebem o sujeito de forma" totalizante, dando "suporte ao desenvolvimento da autonomia docente e trabalhando na contramão do ensino e [...]" da aprendizagem espontaneísta e/ou conteudista.

Tal premissa remete ao sentido de superação da fragmentação do próprio ser humano, o que pressupõe a ausência de hierarquias na formação continuada do profissional docente. Em qualquer espaço social e em qualquer momento histórico, cabe aos professores a capacidade de propor articulação como meio do conhecimento abrangente, integral e a partir de experiências diversas, considerando que não há um único modo de ensinar e aprender. (VITAL; URT, 2019b, p. 251).

Considera-se então que tal formação deve acontecer sobre o pressuposto de não promover a vitimização do professor, mas a partir de uma conduta ético-formativa, 
VITAL, S. C. C.; QUEIROZ, V. B.; URT, S. da C.

fundamentada na defesa e na garantia de seus direitos e no trabalho coletivo. Para que isso aconteça, acredita-se não ser suficiente promover discussões, intervenções e/ou formações somente nos espaços denominados educativos, mas, visto que o adoecimento é um fenômeno que deve ser tema de toda a sociedade, precisa ser discutido e problematizado continuamente, nos mais distintos espaços sociais.

Nesse arcabouço, não se pode negligenciar a concepção do trabalho como atividade fundante e constitutiva da humanidade - no caso do professor, a atividade de ensino, mas também de estudo quando em processo de formação - a fim de que subsidie a compreensão de que por meio da educação também pode-se promover saúde. Ou seja, por meio de uma proposta de formação continuada que proponha a compreensão de que o atual contexto de adoecimento docente reflete as relações sociais de um dado tempo histórico, pode-se pensar um caminho possível de enfretamento.

Isso pressupõe acolher, auxiliar e atender o professor em adoecimento, mas, concomitantemente, pensar e desenvolver propostas formativas transformadoras, que $o$ façam olhar para além da aparência desse fenômeno, compreender suas relações de trabalho e construir objetiva e intencionalmente instrumentos de enfrentamento, buscando alternativas de superação das formas alienadas de desenvolvimento.

Artigo recebido em: 20/08/2020

Aprovado para publicação em: 17/11/2020

CONTINUING EDUCATION AND ILLNESS TEACHER: HISTORICAL-CRITICAL-CULTURAL BASES TO THINK POSSIBILITIES OF COPING

ABSTRACT: The objective of this article is to analyze the design of a bibliographic research about the continuing education of teachers, considering it for human emancipation, and the ways of coping with teaching illness resulting from an alienated and depersonalizing work context. The critical analysis takes place on the theoretical-methodological contribution of Historical-Cultural Psychology and Historical-Critical Pedagogy. As a result, it is understood that thinking about continuous training that contributes to this confrontation, presupposes considering its articulation with the broader problems of society, under the understanding that culture and social relations are fundamental elements in the constitution of the emancipated, critical teacher and capable of understanding social processes. Finally, a transformational formation.

KEYWORDS: Continuing Teacher Education. Illness. Coping. Historical-Cultural Theory.

FORMACIÓN CONTINUA Y ENFERMEDAD DOCENTE: BASES HISTÓRICO-CRÍTICO-CULTURALES PARA PENSAR POSIBILIDADES DE AFRONTAMIENTO

RESUMEN: El objetivo de este artículo es analizar el diseño de una investigación bibliográfica sobre la formación continua del profesorado, considerándola para la emancipación humana, y las 
formas de afrontar la enfermedad docente resultante de un contexto laboral alienado y despersonalizador. El análisis crítica se realiza sobre el aporte teórico-metodológico de la Psicología Histórico-Cultural y la Pedagogía Histórico-Crítica. En consecuencia, se entiende que pensar en una formación continua que contribuya a este enfrentamiento, presupone considerar su articulación con los problemas más amplios de la sociedade, bajo el entendimiento de que la cultura y las relaciones sociales son elementos fundamentales en la constitución del docente emancipado, crítico y capaz de comprender los procesos sociales. Finalmente, una formación transformadora.

PALABRAS CLAVE: Formación Continua del Profesorado. Enfermedad. Afrontamiento. Teoría Histórico-Cultural.

\section{REFERÊNCIAS}

ALONSO, Y. The biopsychosocial model in medical research: the evolution of the health concept over the last two decades. Patient Education and Counseling, La CañadaAlmeria, v. 2, n. 53, p. 239-244. 2004. Disponível em: https://www.researchgate.net/profile/Yolanda_Alonso/publication/8566433_The_biops ychosocial_model_in_medical_research_The_evolution_of the_health_concept_over_t he_last_two_decades/links/5aa62eca0f7e9badd9ab9864/The-biopsychosocial-modelin-medical-research-The-evolution-of-the-health-concept-over-the-last-twodecades.pdf?origin=publication_detail. Acesso em: 3 maio 2020.

ANDRADE, L. V. V. de. Saúde Ocupacional e Trabalho Docente na Universidade: Impactos na Saúde do Professor. 2014. Dissertação (Mestrado em Educação) - Faculdade de Educação, Universidade Federal de Uberlândia, Uberlândia, 2014. Disponível em: https://repositorio.ufu.br/handle/123456789/13988. Acesso em: 3 maio 2020.

ANDRÉ, M. Formar o professor pesquisador para um novo desenvolvimento profissional. In: ANDRÉ, M. (org.). Práticas Inovadoras na Formação de Professores. Campinas: Papirus, 2016. p. 17-34.

AMPUDIA, R; DEODORO, J. Podcast aborda cuidados com a saúde mental do professor em tempos de pandemia. Folha de São Paulo, São Paulo, 2 jun. 2020. Folha na Sala. Disponível em: https://www1.folha.uol .com.br/podcasts/2020/06/podcast-abordacuidados-com-a-saude-mental-do-professor-em-tempos-de-pandemia.shtml. Acesso em: 10 ago. 2020.

ARAUJO, E. S. Mediação e aprendizagem docente. In: Congresso Nacional de Psicologia Escolar e Educacional - CONPE, 9, 2009, São Paulo. Anais [...]. São Paulo: CONPE, 2009. p. $1-16$. 
VITAL, S. C. C.; QUEIROZ, V. B.; URT, S. da C.

BARCELOS, C. Professores lutam contra doenças e até agressões para continuar na profissão. Globoplay, São Paulo, 18 dez. 2019. Disponível em https://globoplay.globo .com/v/8175724/. Acesso em: 30 dez. 2019.

BARROS, M. S. F.; GIROTTO, C. G. G. S. Formação e Ação Docente: o conhecimento científico como eixo essencial no processo de emancipação humana. In: BARROS, M. S. F. et al. (orgs.). Formação, Ensino e Emancipação Humana: desafios da contemporaneidade para educação escolar. Curitiba: CRV, 2019. p. 67-82.

BORGES, K. P. Trabalho e Adoecimento Docente: tensões e conflitos. Cadernos de Pesquisa, Curitiba, v. 9, n. 23, p. 160-187, set-dez. 2014. Disponível em https://interin. utp.br/index.php/a/article/view/531/474. Acesso em: jul. 2020.

CANÁRIO, R. Educação de adultos: um campo e uma problemática. Lisboa: Educa, 2013.

CANGUILHEM, G. O normal e o patológico. 6 ed. São Paulo: Forense Universitária, 2009.

CASTRO, M. M. C e.; AMORIM, R. M. de A. A formação inicial e a continuada: diferenças conceituais que legitimam um espaço de formação permanente de vida. Caderno Cedes, Campinas, v. 35, n. 95, p. 37-55, jan.-abr. 2015.

CHARLOT, B. Relação com o saber, formação dos professores e globalização: questões para a educação hoje. Porto Alegre: ArtMed, 2005.

DUARTE, N. Conhecimento Tácito e Conhecimento Escolar na Formação do Professor (Por que Donald Schön não entendeu Luria). Revista Educação \& Sociedade, Campinas, v. 24, n. 83, p. 601-625, ago. 2003.

IMBERNÓN, F. Formação docente e profissional: forma-se para a mudança e a incerteza. São Paulo: Cortez, 2016.

FACCI, M. G. D. et al. Uso de medicamentos ou medicalização dos professores? Uma discussão sobre as relações de trabalho e adoecimento. In: FACCI, M. G. D.; URT, S. da C. (orgs.). Precarização do Trabalho, Adoecimento e Sofrimento do Professor. Teresina: EDUFPI, 2017. p. 101-112.

GASPARINI, S. M.; BARRETO, S.; ASSUNÇÃO, A. O professor, as condições de trabalho e os efeitos sobre sua saúde. Educação e Pesquisa, São Paulo, v. 31, n. 2, p. 189-199. 2005.

GATTI, B. A. Formação do Professor Pesquisador para o Ensino Superior: desafios. In: Barbosa, Raquel Lazzari Leite (org.). Trajetórias e Perspectivas de Formação de Educadores. São Paulo: Editora UNESP, 2004. p. 433-443.

GONÇALVES, D. V. C. et al. Percepção sobre o Adoecimento entre Estudantes de Cursos da Área da Saúde. Revista Brasileira de Educação Médica, Rio de Janeiro, v. 39, n.1, p. 102- 111. 2015.

Inter-Ação, Goiânia, v.46, n.1, p. 113-130, jan./mar. 2021. Disponível em: <http://dx.doi.org/10.5216/ia.v45i3.65163>. 
LEONTIEV, A. N. Actividad, consciência y personalidade. Buenos Aires: Ediciones Ciências del Hombre, 1978.

LONGAREZI, A. M. Para uma Didática Desenvolvimental e dialética da formação desenvolvimento do professor e do estudante no contexto da educação pública brasileira. Obuchenie Revista de Didática e Psicologia Pedagógica, Uberlândia, v. 1. n.1, p. 187-230. 2017. Disponível em: file:///C:/Users/Andrea/Downloads/39912-1697681-PB\%20(18).pdf. Acesso em: 12 jan. 2020.

MARX, K. Manuscritos econômico-filosóficos. São Paulo: Boitempo, 2004.

MARX, K.; ENGELS, F. A Ideologia Alemã. 10 ed. Tradução de José Carlos Bruni e Marco Aurélio Nogueira. São Paulo, Hucitec, 1996.

MEZZARI, D. P. de S.O Uso do Medicamento pelos Docentes e as Relações de Trabalho: uma compreensão a partir da Psicologia Histórico-Cultural. 2017. Dissertação (Mestrado em Psicologia) - Faculdade de Psicologia, Universidade Estadual de Maringá, Maringá, 2017. Disponível em: http://www.ppi.uem.br/arquivos2019/UEM_PPI_Diana.pdf. Acesso em: out. 2019.

MILLER, S. Prefácio. In: BARROS, M. S. F. et al. (orgs.). Formação, Ensino e Emancipação Humana: desafios da contemporaneidade para educação escolar. Curitiba: CRV, 2019. p. 9-11.

NÓVOA, A. Formação de Professores em Tempo de Pandemia. Webconferência Instituto lungo. 2020. Disponível em: https://www.youtube.com/watch?v=ef3Y QcbERiM Acesso em: 30 jun. 2020.

OLIVEIRA, M. K. de. Ciclos de Vida: algumas questões sobre a psicologia do adulto. Revista Educação e Pesquisa, São Paulo, v. 30, n. 2, p. 211-229, maio-ago. 2004. Disponivel em: https://www.scielo.br/scielo.php?pid =\$1517-97022004000200002 \&script=sci_abstract \&tlng=pt. Acesso em: 20 jun. 2020.

PAPARELLI, R.; SATO, L.; OLIVEIRA, F. de. A saúde mental relacionada ao trabalho e os desafios aos profissionais da saúde. Revista Brasileira Saúde Ocupacional, São Paulo, v. 36, n. 123, p. 118-127, junho. 2011. Disponível em: http://www.scielo.br /scielo.php?script=sci_arttext\&pid=S0303-76572011000100011\&lng=en\&nrm=iso Acesso em: 18 nov. 2019.

PENTEADO, R. Z.; SOUZA NETO, S. de. Mal-estar, sofrimento e adoecimento do professor: de narrativas do trabalho e da cultura docente à docência como profissão. Saúde e Sociedade, São Paulo, v. 28, n. 1, p.135-153. 2019. Disponível em: https://www.scielosp.org/article/sausoc/2019.v28n1/135-153/pt/. Acesso em: 18 nov. de 2020. 
VITAL, S. C. C.; QUEIROZ, V. B.; URT, S. da C.

SAMPAIO, J. J. C. Epidemiologia da imprecisão: processo saúde/doença mental como objeto da epidemiologia. Rio de Janeiro: Editora FIOCRUZ, 1998. Disponível em: http://books.scielo.org. Acesso em: 05 nov. 2019.

SANTOS, L. M. dos.; URT, S. da C.; VITAL, S. C. C. Readaptação docente: qual o sentido atribuído pelo professor? In: FACCl, M. G. D.; URT, S. da C. (orgs.). Precarização do Trabalho, Adoecimento e Sofrimento do Professor. Teresina: EDUFPI, 2017. p. 73-100.

SAVIANI, D. Escola e Democracia - teorias da educação, curvatura da vara, onze teses sobre educação e política. 40 ed. Edição Comemorativa. Campinas: Autores Associados, 2008.

SAVIANI, D. Formação de Professores: aspectos históricos e teóricos do problema no contexto brasileiro. Revista Brasileira de Educação, Rio de Janeiro, v. 14, n. 40, p. 143155, jan-abr. 2009.

SOARES, V. A. B. S.; MARTINS, L. M. Relações entre sofrimento/adoecimento do professor e formação docente. In: FACCl, M. G. D.; URT, S. da C. (orgs.). Precarização do Trabalho, Adoecimento e Sofrimento do Professor. Teresina: EDUFPI, 2017. p. 45-72.

URT. S. da C. Formação de Professores e Educação Integral: concepção de sujeito também integral. In: VALENÇUELA, M. et al. (orgs.). Formação de Professores: linguagem, identidade e cultura. Curitiba: CRV, 2016. p. 63-75.

VITAL, S. C. C.; URT, S. da C. Formação de Professores e Educação Integral: palavras docentes acerca de suas concepções. In: Congresso Nacional de Educação - EDUCERE, 13, 2017, Curitiba. Anais [...]. Curitiba: EDUCERE, 2017. p. 16511-16528. Disponível em: https://educere .bruc.com.br/arquivo/pdf2017/23896_12229.pdf. Acesso em: 18 jul. 2020.

VITAL, S. C. C.; URT, S. da C. Coaching: proposta inovadora para a formação continuada de professores? - reflexões a partir da teoria histórico-cultural e da pedagogia históricocrítica. Revista REVELLI, Inhumas-GO, v. 11, p. 1-22, dez. 2019a. Disponível em: https://www.revista.ueg.br/index. php/revelli/article/view/9489. Acesso em: $20 \mathrm{dez}$. 2019.

VITAL, S. C. C.; URT, S. da C. Pelos caminhos da Educação Integral... Olhares, desafios e concepções de professores. Revista Intermeio, Campo Grande, v. 25, n. 50, p. 237-266, jul-dez. 2019b. Disponível em: file:///C:/Users/soray/Downloads/9427Texto\%20do\%20artigo-30675-1-10-20191206\%20(1).pdf. Acesso em: 20 dez. 2019. 
Soraya Cunha Couto Vital: Doutoranda em Educação e Mestre em Psicologia/ Universidade Federal de Mato Grosso do Sul - UFMS, Brasil. Bolsista CAPES. Graduada em Pedagogia e Letras. Membro do Grupo de Estudos e Pesquisa em Educação e Psicologia - GEPPE/UFMS.

Orcid: https://orcid.org/0000-0001-5716-5605

E-mail: sorayavital@hotmail.com

Vanderlei Braulino Queiroz: Mestrando em Educação/Universidade Federal de Mato Grosso do Sul - UFMS, Brasil. Especialista em Educação, Pobreza e Desigualdade Social/UFMS. Graduado em Psicologia/Universidade Católica Dom Bosco - UCDB. Membro do Grupo de Estudos e Pesquisa em Educação e Psicologia - GEPPE/UFMS.

Orcid: https://orcid.org/0000-0002-9742-1850

E-mail:vanderpsico@outlook.com

SONIA DA CUnha URT: Doutora em Educação. Professora Titular Aposentada dos Programas de Pós-Graduação em Educação e em Psicologia da Universidade Federal de Mato Grosso do Sul - UFMS, Brasil. Professora Pesquisadora Sênior dos Programas de Pós-Graduação em Educação e Psicologia/UFMS. Coordenadora do GEPPE/Diretório $\mathrm{CNPq}$ - Grupo de Estudos e Pesquisa em Psicologia e Educação.

Orcid: https://orcid.org/0000-0002-0309-3498

E-mail: surt@terra.com.br

Este periódico utiliza a licença Creative Commons Attribution 3.0, para periódicos de acesso aberto (Open Archives Iniciative - OAI). 